\title{
Relationship Between Islamic Beliefs and Psychological Well-Being
}

\author{
Bahman Kord Tamini, Atefeh Fadaei \\ University of Sistan and Baluchestan, Zahedan, Iran
}

\begin{abstract}
The purpose of the present study is to explore the relationship between Islamic beliefs and psychological well-being among students from University of Sistan and Baluchestan, Iran. The sample size of this research consists of 300 undergraduate students (148 males and 152 females) that were selected at random and asked to complete the psychological well-being and Islamic beliefs questionnaires. The results showed that there was a significant positive correlation between Islamic beliefs and satisfaction with life, spirituality, happiness and optimism, personal growth, and total scores of well-being. But Islamic beliefs had a significant negative correlation with positive relationship with others. The results of Pearson correlation coefficient did not illustrate any significant correlation between Islamic beliefs and autonomy. The results of stepwise regression revealed that positive relationship with others accounted for $10.6 \%$ and made the largest unique contribution, satisfaction with life accounted for $10.3 \%$, total scores of well-being accounted for 8.3\%, spirituality accounted for 7.6\%, happiness and optimism accounted for $6.3 \%$, and eventually personal growth accounted for $3.3 \%$ of variance in Islamic beliefs of students. There was a significant difference between males and females on scores of satisfaction with life spirituality, happiness and optimism and total scores of well-being, male students obtained higher mean scores than female students, but female students showed higher mean scores than their male counterparts on positive relationship with the above-mentioned issues, and eventually the results did not indicate any significant differences between the two groups on personal growth and autonomy. The results showed that male students had higher mean scores than female students on Islamic believes.
\end{abstract}

Keywords: Islamic beliefs, psychological well-being, students

\section{Introduction}

Religion can be defined as a set of beliefs that concern to the cause, nature, and purpose of life and the universe, especially when regarded as the creation of a supernatural agency, or human beings' relation to that which they regard as holy, sacred, spiritual or divine. According to Koing et al. (2001), "Religion is an organized system of beliefs, practices, rituals and symbols designed to facilitate closeness to the sacred or transcendent (God, higher power or ultimate truth/reality)”. Atran (2002) and Boyer (2001) expressed that "Religion is a great potpourri of ideas and behavior with many independent evolutionary origins outside of religion itself”. Thoresen, Harris, and Oman (2001) revealed that scientific study of religiosity and spirituality, and their relationship with outcome measures, such as health, has expanded since the 1960s and gained 
momentum in recent years (Rogers, Skidmore, Montgomery, Reidhead, \& Reidhead, 2010). Recently, researchers have been interested in studying the impact of religion on health, especially mental health and psychological well-being. Findings demonstrated that there were some associations between religiousness and psychopathology, but these associations were much more between religiousness and mental health (Gartner, Larson, \& Allen, 1991). In a meta-analysis, Bergin (1983) demonstrated that $30 \%$ of the findings showed no relationship with religiousness and mental health, $47 \%$ showed a positive effect and $23 \%$ of the studies showed a negative association (Gartner et al., 1991).

\section{Religiosity and Psychological Well-Being}

Psychological well-being resides in the experience of the individual. It may be defined as the state of feeling healthy and happy, having satisfaction, relaxation, pleasure and peace of mind (Joshi, Kumari, \& Jain, 2008). Evidences showed that religion and wider spirituality cab potentially have both positive and negative influences on the well-being both of individuals and of society at large (Koenig, McCullough, \& Larson, 2000; Diener, 1994). Some researchers have demonstrated that there is a relationship between well-being and spirituality (Gartner, 1996; Mattis \& Jagers, 2001; Seybold \& Hill, 2001). Koenig et al. (2000) have found out a significant positive relationship between religious orientation and well-being. Green and Elliott (2009) indicated that religious identity is positively associated with physical health and well-being whereas liberal religious beliefs are positively associated with physical health and negatively associated with happiness, and they also suggested that religious activities only improve health or well-being among people who identify as religious persons. In a study, Ardelt (2003) showed that purpose in life rather than extrinsic or intrinsic religious orientation was positively related to elders' subjective well-being and negatively associated with fear of death and death avoidance. Religiosity practices can promote some aspects of life, and moreover, reduce the psychological disorders, for example, Koenig, George, and Titus (2004) confirmed that there is a positive link between religion and mental health and also the results showed that religiousness and spirituality consistently predicted greater social support, fewer depressive symptoms, better cognitive function and greater cooperativeness. Gartner (1996) found out positive relationships between religion-spirituality and well-being, marital satisfaction and general psychological functioning.

According to S. Sharma and M. Sharma (2006), prayer has been used as a self-enhancing intervention for centuries. It is inherently a religious affair and activity. Further, a prayer can be general or specific for oneself, for others or for all to a specific deity or may be offered more generally (Joshi, Kumari, \& Jain, 2008). Meraviglia (2006) noted that prayer has been defined as "communication with God as an experience and expression of the human spirit” (p. 2). Investigators have quoted preliminary evidence suggesting that different types of prayer might have differential relationships with effective coping with over all well-being and life satisfaction (Richards \& Bergin, 1997). Maltby, Lewis, and Day (1999) suggested that frequency of personal prayer is a dominant factor in the relationship between religiosity and psychological well-being. Poloma and Pendleton (1991) reveled that colloquial prayers were related to higher levels of well-being and life satisfaction. Francis and Kaldor (2002) demonstrated that there is a positive association between three religion measures (belief in God, personal prayer and church attendance) and psychological well-being. Some of studies showed that prayer has a great impact on some sever illness such as cancer; for example, Levine, Aviv, Yoo, Ewing, and $\mathrm{Au}$ (2008) showed that women who prayed were able to find more positive contributions from their cancer experience than those who did not pray. The results also showed that those who prayed tended to be African 
American or Asian, Catholic or Protestant. Myers and Diener (1995) reported that people who have a meaningful religious faith are more likely to experience a sustained level of happiness.

Evidences show that religious beliefs play an important role in some aspects of individuals' life. Sethi and Seligman (1993) approved that people who have fundamentalist religious beliefs are typically more optimistic hopeful and religiously involved than those who have moderate religious beliefs. In a study, Meraviglia (2004) showed that higher meaning in life scores was associated with higher psychological well-being and lower symptom distress scores and higher prayer scores were also associated with higher psychological well-being scores. Eventually, prayer mediated the relationship between current physical health and psychological responses and explained 10\% of the variance in psychological well-being. Myers and Diener (1995) reported that people who have a meaningful religious faith are more likely to experience a sustained level of happiness. Some of investigators studied the relationship between religion and well-being with regard to culture. Betton (2004) examined the relationship between psychological well-being and self-esteem, social support, worldview, and spirituality in African American and Caucasian college students. Results revealed that African Americans showed higher levels of self-esteem, positive effect and spirituality, while Caucasians showed higher levels of social support. Moreover, the results demonstrated that self-esteem was the best predictor of psychological well-being in Caucasian participants, while spirituality was the strongest predictor of well-being in African American respondents. There exists rare research about relationship between Islamic beliefs and psychological states, especially psychological well-being. In a study, Abdel-Khalek (2010) found out a significant positive relationship between quality of life, subjective well-being and religiosity in Muslim college students.

\section{Gender and Psychological Well-Being}

Some of the researches demonstrated that there is a gap in happiness with regard to gender. Stevenson and Wolfers (2009) showed that there was emerged a gender gap in happiness, in which women in the 1970s reported higher subjective well-being than did men. These declines have continued, and a new gender gap was emerging - one with higher subjective well-being for men. Researchers demonstrated that women under 45 years old tend to be happier than men; but older women are less happy. Inglehart (2010) found out that in a pooled sample of 146,000 respondents from 65 societies, among the youngest group, $24 \%$ of the men and $28 \%$ of the women describe themselves as very happy; but among the oldest group, only $20 \%$ of the women describe themselves as very happy, while $25 \%$ of the men do so. The relationship between gender and well-being reverses itself, moving from a female advantage of four points to a deficit of five points. Given the huge sample size, these differences are highly significant. Farooqi and Tamini (2010) showed that females had higher mean scores on well-being and its dimensions than their male counterparts. But some findings reported reverse results, in a study, Tesch-Römer, Motel-Klingebiel, and Tomasik (2007) revealed that females state more negative emotions than males. Similar findings were emerged from other studies (Costa, Terracciano, \& McCrae, 2001; Feingold, 1994; Hansson, Hilleras, \& Forsell, 2005; Nolen-Hoeksema \& Rusting, 2003; Smith \& Reise, 1998).

Further, much of the current researches have been carried out among western cultures. There is expanding interest in the relationship between psychological well-being and religiosity. Furthermore, the relationship between religiosity (Islamic beliefs) and psychological well-being among an Islamic culture, like Iran, was justified. The purpose of the present study was to examine the relationship between Islamic beliefs and psychological well-being within the context of religious acts among undergraduate students from University of Sistan and Baluchestan, which is one of the most religious and traditional academic centre in Iran. 


\section{Method}

\section{Participants}

The sample size of this research was consisted of 300 undergraduate students (148 males and 152 females) that were selected at random from University of Sistan and Baluchestan, Iran. Participants were asked to complete the psychological well-being and Islamic beliefs questionnaires.

\section{Procedure}

The study was conducted in three faculties (Art and Humanities, Engineering and Science) of University of Sistan and Baluchestan, Iran. After selection of the adequate sample, scales and questionnaires were given to participants, and before responding to questions, the instructions for each part of the scales and questionnaires were adequately explained. The respondents were also assured that their participation in the study was voluntary and their responses would remain confidential and used for research purpose only.

\section{Measures}

PWQ (psychological well-being questionnaire) developed by Zanjani-Tabassi (2004) was used to assess the psychological well-being of students. PWQ consists of 77 items designed to assess six domains common to all students: satisfaction with life, spirituality, happiness and optimism, personal growth, autonomy and positive relationship with others. Each item is to be rated from "Strongly agree" (5) to "Strongly disagree" (1). The whole reliability of this questionnaire is 0.94 , and this coefficient for sub-scales is ranged from 0.90 to 0.62 (Tamini, 2005). In the present research, the overall reliability of this questionnaire using Cronbach's Alpha coefficient method was 0.787 .

IBQ (Islamic beliefs questionnaire) developed by Navidi (1997) was used to assess the religiosity behaviors of students. The IBQ has 45 items and each item is to be rated from "Strongly agree" (5) to "Strongly disagree” (1). In this study, the Cronbach’s Alpha coefficient for whole questionnaire was 0.956.

\section{Data Analyses}

Pearson correlation coefficient was used to explore the relationship between Islamic beliefs and psychological well-being. Results are given in Table 1.

Table 1

Pearson Correlation Coefficient Between Islamic Beliefs and Psychological Well-Being of Students $(N=205)$

\begin{tabular}{|c|c|c|c|c|c|c|c|}
\hline Variable & $\begin{array}{l}\text { Satisfaction } \\
\text { with life }\end{array}$ & Spirituality & $\begin{array}{l}\text { Happiness } \\
\text { optimism }\end{array}$ & $\begin{array}{l}\text { and Personal } \\
\text { growth }\end{array}$ & $\begin{array}{l}\text { Positive } \\
\text { relationship } \\
\text { with others }\end{array}$ & Autonomy & $\begin{array}{l}\text { Total } \\
\text { well-being }\end{array}$ \\
\hline Islamic beliefs & $0.32^{* *}$ & $0.227^{* *}$ & $0.251^{* *}$ & $0.19^{*}$ & $-0.325^{* *}$ & 0.103 & $0.288^{* *}$ \\
\hline
\end{tabular}

Notes. ${ }^{* *} p<0.01 ;{ }^{*} p<0.05$.

The results of Table 1 show that there was a strong, positive, correlation between Islamic beliefs and satisfaction with life ( $r=0.32, p<0.01)$, spirituality ( $r=0.227, p<0.01)$, happiness and optimism $(r=0.251, p$ $<0.01)$, personal growth $(r=0.19, p<0.05)$ and total scores of well-being $(r=0.288, p<0.01)$, with levels of Islamic beliefs being associated with higher levels of satisfaction with life, spirituality, happiness and optimism, personal growth and total scores of well-being. But Islamic beliefs had a significant negative correlation with positive relationship with others $(r=-0.325, p<0.01)$. The results of Pearson correlation coefficient did not illustrate any significant correlation between Islamic beliefs and autonomy. 
To predict the Islamic beliefs from well-being and its dimensions, stepwise regression was conducted and results are shown in Table 2.

Table 2

Stepwise Regression on Well-Being and Its Sub-scales

\begin{tabular}{|c|c|c|c|c|c|c|c|c|}
\hline Variable & B & $\begin{array}{l}\text { Standard } \\
\text { error }\end{array}$ & Beta & $T$ & $R$ & $R^{2}$ & $\begin{array}{c}\mathrm{R}^{2} \\
\text { Change }\end{array}$ & Significance \\
\hline $\begin{array}{l}\text { Positive relationship with } \\
\text { others }\end{array}$ & -0.051 & 0.009 & -0.325 & -5.934 & 0.325 & 0.106 & 0.106 & 0.000 \\
\hline Satisfaction with life & 0.093 & 0.016 & 0.320 & 5.835 & 0.320 & 0.209 & 0.103 & 0.000 \\
\hline Total well-being & 0.199 & 0.038 & 0.288 & 5.195 & 0.288 & 0.292 & 0.083 & 0.000 \\
\hline Spirituality & 0.048 & 0.010 & 0.277 & 4.967 & 0.277 & 0.368 & 0.076 & 0.000 \\
\hline Happiness and optimism & 0.073 & 0.016 & 0.251 & 4.469 & 0.251 & 0.431 & 0.063 & 0.000 \\
\hline Personal growth & 0.025 & 0.008 & 0.181 & 3.180 & 0.181 & 0.464 & 0.033 & 0.002 \\
\hline
\end{tabular}

As shown in Table 2, positive relationships with others (Beta $=-0.325, p<0.001$ ) was negatively related with Islamic beliefs, but satisfaction with life (Beta $=0.320, p<0.001$ ), total well-being (Beta $=0.227$, $p<0.001$ ), spirituality (Beta $=0.228, p<0.001$ ), happiness and optimism (Beta $=0.251, p<0.001$ ) and personal growth (Beta $=0.181, p<0.01$ ) had a significant positive relation with Islamic beliefs. Autonomy failed enters into the regression equation, which shows that it was not significantly associated with Islamic beliefs. Positive relationship with others accounted for $10.6 \%$ and made the largest unique contribution, satisfaction with life accounted for $10.3 \%$, total scores of well-being accounted for $8.3 \%$, spirituality accounted for $7.6 \%$, happiness and optimism accounted for $6.3 \%$, and eventually, personal growth accounted for $3.3 \%$ of variance in Islamic beliefs of students.

An independent sample $t$-test was conducted to compare the well-being and its dimensions scores for male and female students, and the results are shown in Table 3.

Table 3

Showing Mean, SD and T-Value of Male and Female Students on Well-Being and Its Sub-scales $(N=300)$

\begin{tabular}{|c|c|c|c|c|c|c|}
\hline Variable & Gender & Mean & $S D$ & $D f$ & $t$-value $(t)$ & Significance \\
\hline \multirow[t]{2}{*}{ Satisfaction with life } & Male & 47.48 & 8.36 & 298 & \multirow{2}{*}{2.865} & \multirow{2}{*}{0.004} \\
\hline & Female & 45.17 & 7.79 & & & \\
\hline \multirow[t]{2}{*}{ Spirituality } & Male & 34.27 & 5.10 & 298 & \multirow{2}{*}{3.101} & \multirow{2}{*}{0.002} \\
\hline & Female & 32.55 & 4.47 & & & \\
\hline \multirow[t]{2}{*}{ Happiness and optimism } & Male & 47.52 & 7.56 & 298 & \multirow{2}{*}{4.074} & \multirow{2}{*}{0.000} \\
\hline & Female & 43.48 & 8.45 & & & \\
\hline \multirow[t]{2}{*}{ Personal growth } & Male & 22.05 & 3.87 & 298 & \multirow{2}{*}{-0.770} & \multirow{2}{*}{0.442} \\
\hline & Female & 22.39 & 3.78 & & & \\
\hline \multirow[t]{2}{*}{ Positive relationship with others } & Male & 30.69 & 4.54 & 298 & \multirow{2}{*}{-3.88} & \multirow{2}{*}{0.000} \\
\hline & Female & 32.63 & 4.10 & & & \\
\hline \multirow[t]{2}{*}{ Autonomy } & Male & 27.85 & 3.59 & 298 & \multirow{2}{*}{-0.361} & \multirow{2}{*}{0.719} \\
\hline & Female & 27.99 & 3.22 & & & \\
\hline \multirow[t]{2}{*}{ Total well-being } & Male & 209.97 & 19.35 & 298 & \multirow{2}{*}{2.56} & \multirow{2}{*}{0.01} \\
\hline & Female & 204.23 & 19.37 & & & \\
\hline
\end{tabular}

As it is observed from Table 3, there was a significant difference in scores for males $(M=47.48, S D=$ 8.36), and females on satisfaction with life $\left(M=45.17, S D=7.79 ; t_{(298)}=2.865, p=0.004\right)$, there was a 
significant difference in scores for males $(M=34.27, S D=5.10)$ and females on spirituality $(M=32.55, S D=$ $\left.4.47 ; t_{(298)}=3.101, p=0.002\right)$, there was significant difference in scores for males $(M=47.52, S D=7.56)$, and females on happiness and optimism $\left(M=43.48, S D=8.45 ; t_{(298)}=4.074, p=0.000\right)$, there was significant difference in scores for males $(M=209.97, S D=19.35)$ and females on total well-being $(M=204.23, S D=$ $\left.19.37 ; t_{(298)}=2.56, p=0.01\right)$, and also there was significant difference in scores for males $(M=30.69, S D=$ $4.54)$, and females on positive relationship with others $\left(M=32.63, S D=4.10 ; t_{(298)}=-3.88, p=0.000\right)$. Male students obtained higher mean scores than female students on satisfaction with life, spirituality, happiness and optimism, and total scores of well-being, but female students showed higher mean scores than their male counterparts on positive relationship with others, and eventually, the results did not indicate any significant differences between two groups on personal growth and autonomy.

Table 4

Showing Mean, SD and T-Value of Male and Female Students on Islamic Beliefs $(N=300)$

\begin{tabular}{llllll}
\hline Gender & Mean & $S D$ & $D f$ & $t$-value $(t)$ & Significance \\
\hline Male & 96.67 & 29.98 & 298 & 2.93 & 0.004 \\
Female & 87.21 & 25.77 & & & \\
\hline
\end{tabular}

The results from Table 4 reveal that there was significant difference in scores for males $(M=96.67, S D=$ 29.98) and females on Islamic beliefs $\left(M=87.21, S D=25.77 ; t_{(298)}=2.93, p=0.004\right)$, it was found out that male students had higher mean scores than female students.

\section{Discussion}

Recently, many of the researchers and practitioners have considered the religion as a main factor which has an obvious impact on behavioral and psychological states. Many researchers suggest that current pain of human is lack of existential, causeless feelings and absurdity in their lives and these feelings have undeniable effect on individuals' mental health and happiness. Therefore, the purpose of the current study is to find out the relationship between Islamic beliefs and psychological well-being among students form University of Sistan and Baluchestan, Iran. Researches around the world have illustrated that religiosity has a great relationship with psychological well-being, happiness and life satisfaction, so our findings indicated that there was emerged a significant positive correlation between Islamic beliefs and satisfaction with life, spirituality, happiness and optimism, personal growth and total scores of well-being. But Islamic beliefs had a negative correlation with positive relationship with others sub-scale. The results did not illustrate any significant correlation between Islamic beliefs and autonomy. The results of this study are in conformity with the research of Koenig et al. (2000), Gartner (1996), Betton (2004), Sethi and Seligman (1993), Abdel-Khalek (2010), and Richards and Bergin (1997) suggested that different types of prayer might have differential relationships with effective coping with over all well-being and life satisfaction. As noted by Poloma and Pendleton (1991), colloquial prayers were related to higher levels of well-being and life satisfaction. Maltby et al. (1999) suggested that frequency of personal prayer is a dominant factor in the relationship between religiosity and psychological well-being. It seems that Islamic beliefs or religiosity has a positive and direct impact on well-being, life satisfaction and happiness, and moreover, religious people are more hopeful to their life, and their mental and social maturity is also high. Worship brings peace and serenity in individuals' lives, and also religious individuals pay more respect to themselves and others, so their self-esteem, self-acceptance, self-confidence, 
etc., increase. Having a strong spiritual relationship with God is caused that we master on our life and environment, despite the above mentions, results suggested that students who exhibited lower mean scores on positive relationships with others were not sociable, because they believed that others' behaviors and thoughts might have negative impact on their personality and also bring some changes in their life styles.

For responding to the second question of research, stepwise regression was applied and findings showed that positive relationship with others sub-scale was related and had a negative relation with Islamic beliefs. Other dimensions of well-being, such as satisfaction with life, overall well-being, spirituality, happiness and optimism and personal growth had positive relation with Islamic beliefs, but autonomy sub-scale failed enter into the regression equation, which showed that it was not significantly associated with Islamic beliefs. Similar findings were reported by Meraviglia (2004), he showed that higher meaning in life scores was associated with higher psychological well-being and lower symptom distress scores and also higher prayer scores were associated with higher psychological well-being scores. Green and Elliott (2009) believed that religious identity has positive association with physical health and well-being.

The results of this study emerged statistically significant difference between male and female students' well-being, i.e., male students significantly obtained higher mean scores on satisfaction with life, spirituality, happiness and optimism and total scores of well-being as compared to female students, but female students showed higher mean scores than their male counterparts on positive relationship with others, finally, the results did not indicate any significant differences between two groups on personal growth and autonomy. Results of this study are in accordance to the results of Stevenson and Wolfers (2009), Tesch-Römer, Motel-Klingebiel, and Tomasik (2007), Costa et al. (2001), Hansson et al. (2005), and Tesch-Römer and Wurm (2006). Male students reported higher Islamic beliefs and thoughts than their female counterparts, as earlier mentioned, it is speculated that religion has a great impact on our thoughts, life style and behavior; and moreover, it can have effect on some aspects of our life, such as life satisfaction, happiness, self-esteem and well-being. It seems that religious activities and spirituality is a treatment to reduce the psychological pains.

\section{References}

Abdel-Khalek, A. M. (2010). Quality of life, subjective well-being, and religiosity in Muslim college students. Quality of Life Research Journal, (June 2010) (in press).

Ardelt, M. (2003). Effects of religion and purpose in life on elders' subjective well-being and attitudes toward death. Journal of Religious Gerontology, 14(4), 55-77.

Atran, S. (2002). In Gods we trust: The evolutionary landscape of religion. New York: Oxford University Press.

Bergin, A., Masters, K., \& Richards, P. (1987). Religiousness and mental health reconsidered: A study of an intrinsically religious sample. Journal of Counseling Psychology, 34(2), 197-204.

Betton, A. C. (2004). Psychological well-being and spirituality among African American and European American college students (Unpublished doctoral dissertation, the Ohio State University).

Boyer, P. (2001). Religion explained: The evolutionary origins of religious thought. New York: Basic.

Costa, P. T. Jr., Terracciano, A., \& McCrae, R. R. (2001). Gender differences in personality traits across cultures: Robust and surprising findings. Journal of Personality and Social Psychology, 81, 322-331.

Diener, E. (1994). Assessing subjective wellbeing: Progress and opportunities. Social Indicator Research, 31, $103-157$.

Farooqi, M. I., \& Tamini, B. K. (2010). A study of life satisfaction, general health and well-being of students. Indian Journal of Psychology and Mental Health, 4(6), 24-32.

Feingold, A. (1994). Gender differences in personality: A meta-analysis. Psychological Bulletin, 116, 429-445.

Francis, L., \& Kaldor, P. (2002). The relationship between psychological well-being and Christian faith and practice in an Australian population sample. Journal for the Scientific Study of Religion, 41(1), 179-184.

Gartner, J. (1996). Religious commitment, mental health, and pro-social behavior: A review of the empirical literature. In E. P. Shafranske (Ed.), Religion and the clinical practice of psychology (pp. 187-214). Washington, D. C.: American 
Psychological Association.

Gartner, J., Larson, D., \& Allen, G.. (1991). Religious commitment and mental health: A review of the empirical literature. Journal of Psychology and Theology, 19(1), 6-25.

Green, M., \& Elliott, M. (2009). Religion, health, and psychological well-being. Paper presented at the Annual Meeting of the American Sociological Association, Hilton San Francisco, San Francisco, C. A. Online. Retrieved from http://www.allacademic.com/meta/p307430_index.html.

Hansson, A., Hilleras, P., \& Forsell, Y. (2005). Well-being in an adult Swedish population. Social Indicators Research, 74, 313-325.

Inglehart, R. (2010). Gender, aging, and subjective well-being. International Journal of Comparative Sociology, 43(35), $391-408$.

Joshi, S., Kumari, S., \& Jain, M. (2008). Religious belief and its relation to psychological well-being. Journal of the Indian Academy of Applied Psychology, 34(2), 345-354.

Koeing, H. G., McCullough, M., \& Larson, D. B. (2001). Handbook of religion and health: A century of research reviewed. New York: Oxford University Press.

Koenig, H. G., George, H. K., \& Titus, P. (2004). Religion, Spirituality, and health in medically ill hospitalized older patients. Journal of the American Geriatrics Society, 52, 554-562.

Koenig, H. G., McCullough, M. E., \& Larson, M. D. (2000). Handbook of religion and health. New York: Oxford University Press.

Levine, E. L., Aviv, C., Yoo, G., Ewing, C., \& Au, A. (2008). The benefits of prayer on mood and well-being of breast cancer survivors. Support Care Cancer, 17, 295-306.

Maltby, J., Lewis, C. A., \& Day, L. (1999). Religious orientation and psychological well-being: The role of the frequency of personal prayer. British Journal of Health Psychology, 4, 363-378.

Mattis, J., \& Jagers, R. (2001). A relational framework for the study of religiosity and spirituality in the lives of African Americans. Journal of Community Psychology, 29(5), 519-539.

Meraviglia, M. G. (2004). The effects of spirituality on well-being of people with lung cancer, Oncol Nurs Forum, 31(1), 89-94.

Meraviglia, M. G. (2006). Effects of spirituality in breast cancer survivors. Oncol Nurs Forum, 33(1), E1-7.

Myers, D. G., \& Diener, E. D. (1995). Who is happy?. Psychological Science, 6, 10-19.

Navidi, A. (1997). Islamic believes questionnaire. Tehran: The School of Behavioral Science Research, Sina (Ravan Tajhiz).

Nolen-Hoeksema, S., \& Rusting, C. L. (2003). Gender differences in wellbeing. In D. Kahneman, E. Diener, \& N. Schwarz (Eds.), Wellbeing: The foundations of hedonic psychology (pp. 330-350). New York: Russel Sage Foundation.

Poloma, M., \& Pendleton, B. (1991). The effects of prayer and prayer experience on measures of general well-being. Journal of Psychology and Theology, 10, 71-83.

Richards, P. S., \& Bergin, A. E. (1997). A spiritual strategy for counseling and psychotherapy. Washington D. C.: American Psychological Association.

Rogers, D. L., Skidmore, S. T., Montgomery, G. T., Reidhead, M. A., \& Reidhead, V. A. (2010). Spiritual integration predicts self-reported mental and physical health. Journal of Religion and Health, 49(5) (in press).

Sethi, S., \& Seligman, M. E. P. (1993). Optimism and fundamentalism. Psychological Science, 4, 256-259.

Seybold, K., \& Hill, P. (2001). The role of religion and spirituality in mental and physical health. Current Directions in Psychological Science, 10(1), 21-24.

Sharma, S., \& Sharma, M. (2006). Sustaining and enhancing health/well-being of Indian students: The role of certain spiritual and religious interventions. Psychological Studies, 51, 113-118.

Smith, L. L., \& Reise, S. P. (1998). Gender differences on negative affectivity: An IRT study of differential item functioning on the multidimensional personality questionnaire stress reaction scale. Journal of Personality and Social Psychology, 75, 1350-1362.

Stevenson, B., \& Wolfers, J. (2009). The paradox of declining female happiness. American Economic Journal: Economic Policy, $1(2), 190-225$.

Tamini, K. B. (2005). The role of remarriage in mental health of martyr families and their children (Unpublished master's thesis, University of Tehran).

Tesch-Römer, C., Motel-Klingebiel, A., \& Tomasik, M. J. (2007). Gender differences in subjective well-being: Comparing societies with respect to gender equality. Social Indicators Research, 85(2), 329-349.

Thoresen, C. E., Harris, A. H. S., \& Oman, D. (2001). Spirituality, religion and health: Evidence, issues and concerns. In T. G. Plante, \& A. C. Sherman (Eds.), Faith and health: Psychological perspectives (pp. 15-52). New York: Guilford Press.

Zanjani-Tabassi, R. (2004). Preliminary construction and normalization of the well-being questionnaire (Unpublished master's thesis, University of Tehran). 